\title{
O potencial significativo de games na educação: análise do Minecraft
}

\author{
Luciana Coutinho Pagliarini de Souza \\ Doutora em Comunicação e Semiótica pela PUC-SP. É professora do Programa de Mestrado em \\ Comunicação e Cultura na Uniso. \\ E-mail: luciana.souza@prof.uniso.br
}

\author{
Angelica Caniello \\ Mestra em Comunicação e Cultura na Uniso, onde leciona Pesquisa Mercadológica, Sociologia \\ da Comunicação e Marketing. \\ E-mail: angelica.caniello@prof.uniso.br
}

Resumo: $O$ presente artigo apresenta reflexões sobre o potencial significativo de games introduzidos no ambiente escolar como prática interdisciplinar. Para fins de análise, utilizamos os princípios de aprendizagem dos bons games, listados por $\mathrm{Gee}^{1}$ e delimitamos este estudo qualitativo na análise da linguagem de um game voltado para adolescentes que cursam o ensino fundamental II: Minecraft. Entre os resultados, destacamos que os games podem proporcionar diferentes tipos de experiência, aprendizagem e níveis de interação e ludicidade. A inserção de uma linguagem educacional (formal e informal) dialógica, lúdica, hipermidiática possibilita que o aluno seja um agente ativo do seu aprendizado, produtor e multiplicador de novos conhecimentos.

Palavras-chave: game educativo; linguagem hipermidiática; processos cognitivos; ludicidade; Minecraft.
Abstract: This paper presents reflections on the significant potential of games introduced in the school environment as an interdisciplinary practice. For analysis purposes, we use the principles of good game, good learning - listed by Gee ${ }^{1}$ - and delimit this qualitative study on the analysis of the language of a game for teenagers attending elementary school II: Minecraft. Among the results, we emphasize that games can provide different kinds of experiences, learning and levels of interaction and playfulness. The introduction of an educational language (formal and informal) that is dialogical, playful and hypermediatic allows the student to be an active agent of his learning, a producer and multiplier of new knowledge.

Keywords: educational game; hipermediatic language; cognitive processes; playfulness; Minecraft.
$1 \mathrm{GEE}$, J., P. Bons videogames e boa aprendizagem. Revista Perspectiva, Florianópolis, v. 27 n. 1, jan./ jun. 2009. Disponível em: $<w w w$.perspectiva.ufsc. br>. Acesso em: 1 jul. 2013.

Recebido: 05/02/2015

Aprovado: 09/03/2015 
comunicação \& educação • Ano XX • número 2 • jul/dez 2015

\section{INTRODUÇÃO}

A educação formal, que tradicionalmente utiliza uma linguagem linear e verbal, concorre com a linguagem hipertextual da web que é mais dinâmica e potencialmente mais interativa e lúdica. Entre as mídias eletrônicas, certamente a que exerce mais fascínio entre as crianças e os adolescentes em idade escolar é o game.

Além de produto de entretenimento de grande sucesso comercial, o game constitui-se de uma linguagem capaz de auxiliar no desenvolvimento de habilidades cognitivas e competências exigidas pela sociedade atual. Acrescida do componente lúdico, essa linguagem se torna muito sedutora para o público infanto-juvenil.

Para Soares, Tupy e Schwartz ${ }^{1}$ os games, tanto como mídia quanto como prática interdisciplinar, podem ser aplicados a processos considerados educomunicativos. Porém, os games não são todos iguais. A partir de um levantamento cuidadoso no Portal do Professor, desenvolvido pelo Ministério de Educação, constatamos que muitos jogos digitais, do gênero educacional, utilizados nas instituições de ensino e fora delas, repetem a mesma lógica do professor dentro da sala de aula. A partir daí, irrompeu a questão que direcionou o interesse por este estudo: o que difere um game capaz de promover um aprendizado interativo e lúdico de outro que se limita a ser uma transposição da apostila impressa em versão digital? Quais princípios requeridos na constituição da linguagem dos games favorecem a cognição? Entre as habilidades cognitivas que a frequência aos games tende a desenvolver, Santaella² destaca: aptidão lúdica, capacidade de experimentar novas situações como forma de solução de problemas, habilidade de improvisar, explorar e descobrir, capacidade de interpretar e construir modelos dinâmicos reais, capacidade de compartilhar conhecimento e comparar opiniões: "em quaisquer campos em que se aplicam, os jogos digitais levam os seus usuários a aprender sem perceber, de forma natural, além de desenvolver a habilidade para se trabalhar em equipe".

Representante notório da área de Educomunicação, Orozco Gómez ${ }^{3}$ reforça

1 SOARES, I.O.; TUPY, F; SCHWARTZ, G. Educomunicação e Videogames: uma abordagem de interface aplicada para Gestão. XI SBGAMES. Brasília, nov. 2012.

2 SANTAELLA, Lucia. Game também é cultura? Seminário Internacional Rumos do Jornalismo Cultural, São Paulo, 2012. Disponível em: <www. youtube.com/watch?v= NZr5FnjWzTE $>$. Acesso em: 25 abr. 2013.

3 OROZCO GÓMEZ, G. Educomunicação: recepção midiática, aprendizagens e cidadania. São Paulo: Paulinas, 2014, p. 77. 4 GEE, op. cit. que a prática do videojogo ( game) envolve habilidades e reflexões em áreas do pensamento ou relacionadas a outras inteligências que não são estimuladas a partir das aprendizagens formais da escola.

$\mathrm{O}$ autor vislumbra uma transformação nos paradigmas do conhecimento, qual seja: passa-se do modelo centrado na transmissão de informação e de conhecimento por meio de repetição, memorização, reprodução para um paradigma centrado em exploração, tentativa e erro, experimentação, que tem na criatividade e não na reprodução o diferencial. É nesse novo paradigma que se deve "dar sentido" às novas tecnologias para a educação e, particularmente, aos videojogos.

Prosseguindo em nossas reflexões acerca dos princípios constituintes do game que contribuem para o desenvolvimento de habilidades de modo a favorecer o aprendizado dialógico e transformador, discorremos sobre a linguagem do game para, então, apresentarmos a análise do Minecraft à luz dos princípios de aprendizagem listados por $\mathrm{Gee}^{4}$. 


\section{A LINGUAGEM DO GAME: LUDICIDADE E INTERAÇÃO}

O jogo, detalha Santaella ${ }^{5}$, envolve tensão, equilíbrio, compensação, contraste, variação, solução, união e desunião: "sem tensão não há jogo. Disso derivam as categorias do lúdico: ordem, tensão, movimento, mudança, solenidade, ritmo e entusiasmo". Para a autora, o lúdico é o lugar no qual as forças da razão e da sensibilidade se fazem presentes e, por ser um componente fundamental em um jogo, é o maior responsável pelo potencial de desenvolvimento de habilidades socioafetivas e cognitivas.

O fator lúdico permeia a nossa vida social. O espírito de competição lúdica, explica Huizinga ${ }^{6}$, enquanto impulso social, é mais antigo que a cultura, e a própria vida está toda penetrada por ele, "como por um verdadeiro fermento". Portanto, na visão do autor, o jogo é uma atividade cultural, com função social. Da mesma forma que o homem é comunicativo por natureza, também é lúdico, "por isso associamos o ato de jogar não apenas a um momento de lazer, mas a algo presente nos demais segmentos da vida"7. Por essa razão, Gilson $\mathrm{Schwartz}^{8}$ afirma que os jogos educativos precisam agradar principalmente seu público-alvo, no caso, os alunos. "O game não pode ser chato. Existem muitos jogos educacionais que são chatos porque repetem a mesma lógica do professor dentro da sala de aula, cobrando do aluno uma resposta." Nesses games as escolhas são limitadas e predeterminadas. Ao jogador cabe apenas o esforço de responder a alternativa certa, que normalmente é baseada em conteúdos trabalhados pelo professor em sala de aula.

Corrobora essa ideia Santaella ${ }^{9}$ ao afirmar que o maior desafio dos jogos com propósitos educacionais "é oferecer para o aprendiz um ambiente em que os usuários queiram estar, queiram explorar e fiquem entretidos em tal intensidade, que aprendam sem sentir que estão aprendendo". Para isso, sugere a autora, os games educativos devem se espelhar no sucesso dos games comerciais.

Afirma ainda ${ }^{10}$ que a interatividade e a imersão são intrínsecas na comunicação digital, mas nos games ela varia, pois vai dos níveis mais baixos - em que o jogador é simplesmente reativo — até um limiar mais alto, quando o programa é complexo, imprevisível e não linear. Neste último, o jogador é envolvido por esse espaço como na realidade virtual, permitindo ao usuário-interlocutor-fruidor a liberdade de participação e intervenção: "é justamente um ideal desse tipo que o game como produto criador visa atingir", conclui.

\section{O POTENCIAL SIGNIFICATIVO DO MINECRAFT}

O game Minecraft foi criado pelo suíço Markus "Notch” Persson, em 2009. Até o início de 2014, já havia vendido mais de 35 milhões de cópias ${ }^{11}$, com mais de 100 milhões de usuários registrados em seu site oficial. Originalmente feito para PC, o jogo está disponível também para as consoles PlayStation3 e Xbox360 e pode ser jogado off-line ou on-line, sozinho ou com outros players.
5 SANTAELLA, Lucia. Comunicação ubíqua. São Paulo: Paulus, 2013, p. 252.

6 HUIZINGA, Johan. Homo ludens. São Paulo: Perspectiva, 1999, p. 193.

7 SOARES, I.O.; TUPY, F; SCHWARTZ, G., op. cit. p. 50.

8 SCHWARTZ, Gilson. Game "Conflitos globais" tenta quebrar paradigma e colocar jogos na escola. Globo.com, mar. 2010. Disponível em: <http:// g1.globo.com/Noticias/ Games/ 0,MUL1534669 $9666,00 . \mathrm{html}>$. Acesso em: 30 jun. 2013.

9 SANTAELLA, Lucia, 2013, op. cit., p. 262.

10 Idem, 2004, p. 4.

11 FENÔMENO mundial, jogo Minecraft pode ganhar adaptação para o cinema. Folha de São Paulo. São Paulo, fev. 2014. Disponível em: <www1.folha.uol.com.br/ tec/2014>. Acesso em: 15 maio 2014. 
Esse game não nasceu como gênero educativo, mas foi adotado por mais de mil escolas, em todo o mundo, nas diversas disciplinas curriculares.

O Minecraft segue o estilo sandbox (caixa de areia), de mundo aberto, cheio de possibilidades, permitindo que o jogador possa seguir o caminho que quiser e tomar suas próprias decisões sobre o que fazer. Com o seu avatar, o jogador pode criar de pequenas casas a grandes castelos e cidades inteiras. Para tanto, utilizam-se de blocos minerados, daí o nome do jogo.
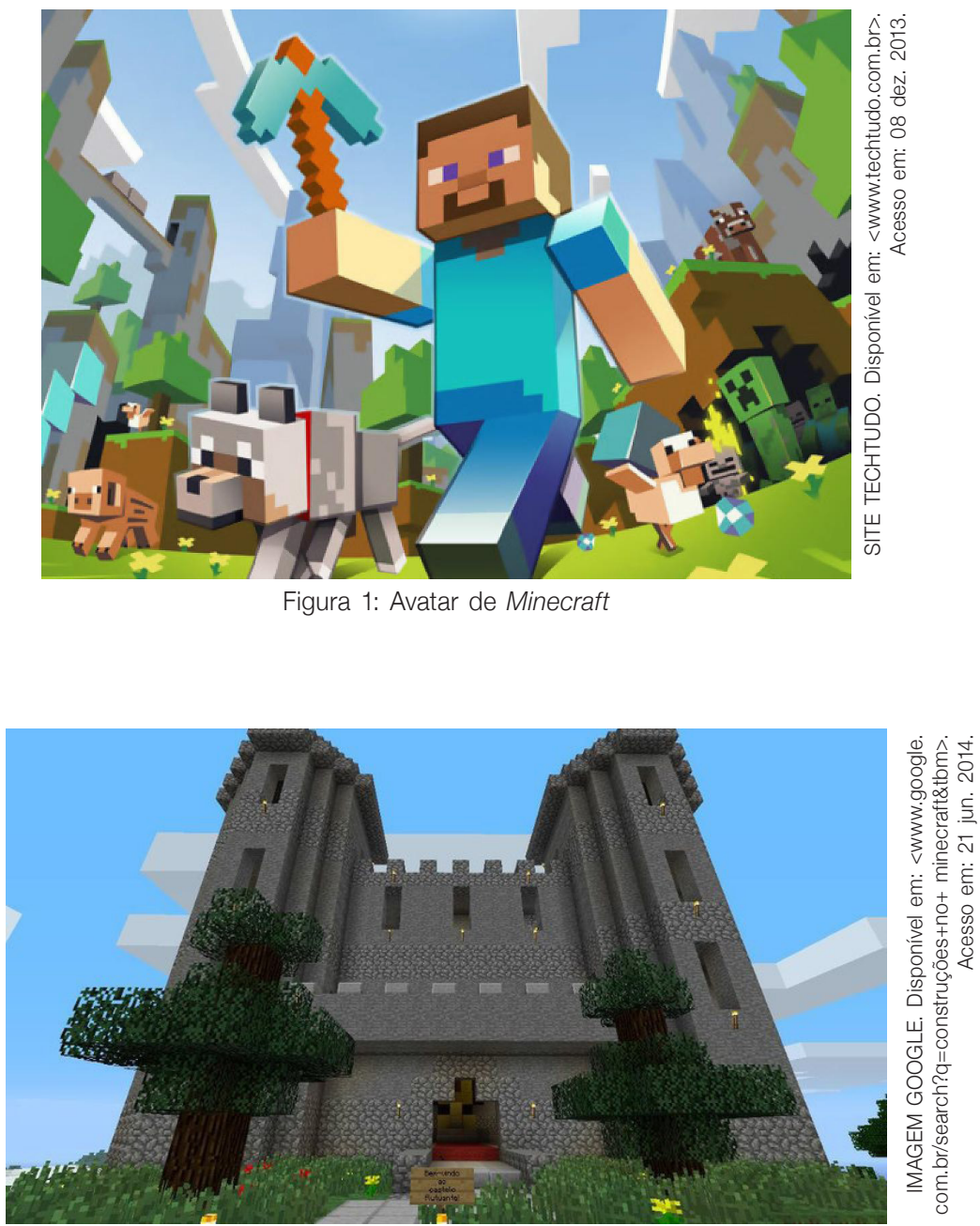

Figura 2: Construção de um castelo em Minecraft

O game não é simplesmente um simulador arquitetural; o propósito último é explorar o cenário, colher objetos, combater a fome e criar formas de se proteger contra monstros (chamados de mobs) que saem à noite, como aranhas, esqueletos, zumbis. Utilizando materiais como madeira, areia, carvão, pedra, diamante, o jogador constrói o que lhe serve, segundo os seus propósitos. Conforme o jogador progride, surgem novas necessidades, tais como: criar uma picareta mais robusta, carros de mina para se mover de forma mais eficiente pelo mundo, tochas para iluminar fendas escuras ou planejar novas combinações entre os blocos (pedra, 
ferro, vidro) para obter peças mais complexas que podem ajudar a construir, por exemplo, um forte para se proteger contra os inimigos.

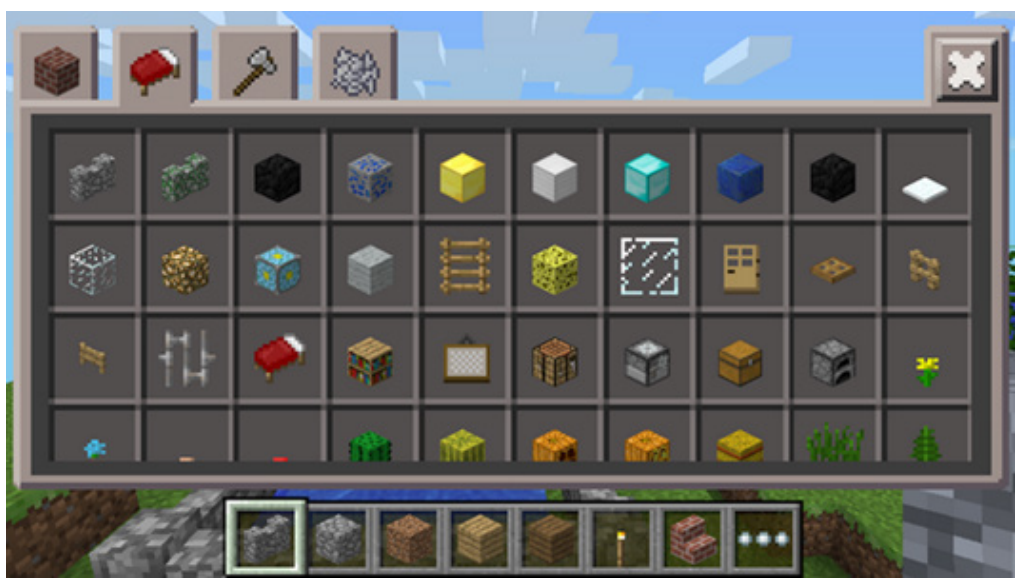

Figura 3: Inventário do Minecraft

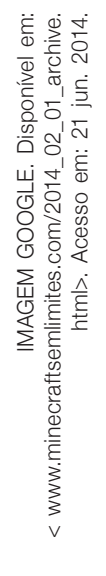

Para os principiantes que não queiram se aventurar no jogo sem conhecimento prévio, existem muitos tutoriais no YouTube e em sites criados pelos próprios fãs que ensinam o passo a passo.

Mesmo com uma aparente liberdade de locomoção e de tomada de decisões por parte do gamer, o jogo possui regras e delimitações, comuns e necessárias a todos os jogos, como afirma Huizinga ${ }^{12}$ ao falar sobre as características formais do jogo: "todo jogo tem suas regras. São estas que determinam aquilo que vale dentro do mundo temporário por ele circunscrito".

Um aspecto que difere o Minecraft da maioria dos games de sucesso comercial é o fato de não ter um design gráfico inovador ou chamativo; o cenário é formado completamente por blocos, sendo até o sol um grande quadrado com pixels ${ }^{13}$ bem visíveis. O seu conceito de construção e paisagem no espaço virtual remete o jogador aos blocos de Lego.

Outra interessante característica do Minecraft é a possibilidade de o jogador cocriar novos jogos dentro da plataforma. São os chamados mods (modificadores), versões desenvolvidas a partir de um modelo preexistente para propiciar novas experiências aos interatores.

$\mathrm{Na}$ China, alunos de várias escolas adotaram o Minecraft para aprender literatura, reconstruindo cenários de romances clássicos. Na Austrália, combinações de matéria-prima para fazer novos produtos são usadas nas aulas de Matemática. Além das escolas, Minecraft também virou base para projetos sociais. Até 2016, a ONU pretende revitalizar mais de 300 espaços urbanos no mundo com a ajuda do jogo. O projeto, chamado Bloco por Bloco, é coordenado pelo Habitat, escritório da ONU para desenvolvimento urbano e ambiental, e busca envolver jovens na recuperação de áreas abandonadas. Para isso, os locais são recriados dentro do game e os jogadores, convidados a modificá-los virtualmente. O primeiro local a ser revitalizado é um parquinho na periferia de Nairóbi (Quênia).
12 HUIZINGA, op. cit., p. 10.

13 Pixel é o menor ponto que forma uma imagem digital, e o conjunto de milhares de pixels forma a imagem inteira. 


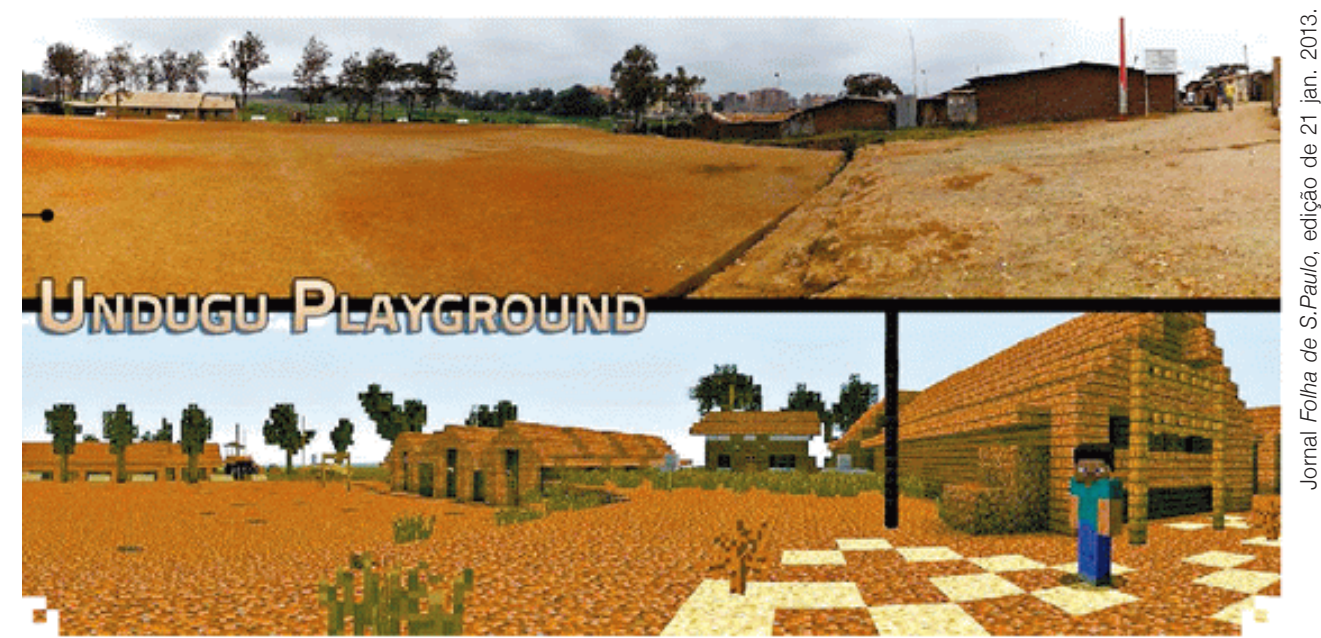

Parque Udungu, em Nairóbi (Quênia), primeiro participante do projeto da ONU

Figura 4: Projeto Bloco por Bloco

Feita essa descrição do game, retornamos à questão inicial do artigo: o que torna esse game educativo de fato? Ou seja, que princípios nele intrínsecos favorecem a cognição?

\subsection{Os princípios de aprendizagem do Minecraft}

Neste tópico tomamos a lista de princípios de aprendizagem criada por Gee ${ }^{14}$. O teórico defende a ideia que os bons games prendem a atenção dos jogadores porque são feitos com base em princípios bem estruturados de jogabilidade e de aprendizagem. Esses princípios, defende o teórico, demonstrariam o seu grande potencial enquanto linguagem que promove múltiplas habilidades cognitivas. Vejamos como esses princípios estão presentes no Minecraft.

O primeiro é denominado identidade. Nele a aprendizagem ocorre, para Gee, quando o aprendiz assume o compromisso de ver e de valorizar o trabalho e o mundo da forma como o fazem os trabalhadores reais. O Minecraft tem esse potencial e o projeto Bloco por Bloco, idealizado pela ONU, é um exemplo de aplicação que leva o usuário a se comprometer com problemas sociais.

O segundo, interação, se dá no contexto da relação dialógica entre os jogadores, que compartilham experiências nas comunidades e fóruns virtuais e dentro do próprio jogo, quando atuam solidariamente, no modo multiplayer.

A produção, segundo Gee, ocorre mesmo no nível mais simples em que os jogadores codesenham os jogos pelas ações que executam e as decisões que tomam. Os jogadores de Minecraft são cocriadores do universo do jogo e capazes de modificá-lo, livremente, procurando novas significações que fazem com que o game não se torne monótono e exaustivo.

Quanto aos riscos/boa ordenação dos problemas, os bons games reduzem as consequências das falhas dos jogadores: quando erram, eles sempre podem voltar ao último jogo que salvaram. Os jogadores são assim encorajados a correr 


\section{O potencial significativo de games na educação \\ - Luciana Coutinho Pagliarini de Souza e Angelica Caniello}

riscos, a explorar, a tentar coisas novas. O avatar, dentro do mundo de Minecraft, corre muitos riscos, mas pode sempre evoluir a partir das conquistas. $\mathrm{O}$ jogador pode salvar as construções e retomá-las até alguns dias depois, além de armazenar as ferramentas e blocos minerados. Conforme o jogador explora as potencialidades de um mundo inicialmente vazio, ganha experiência e pode criar novas formas de jogar. Quanto mais familiaridade e experiência acumula, mais o jogador busca novos e mais complexos desafios.

Bons jogos permitem que os jogadores solucionem problemas de diferentes maneiras, com diferentes atributos dos avatares. Os jogadores, para Gee, deveriam ter a real sensação de agência e controle. Essas habilidades caracterizam customização/agência. Esses são dois pontos fortes do Minecraft, que é totalmente customizável, segundo os interesses e desejos dos seus jogadores. Dependendo do modo - criative, survival, hardcore, adventure ou spectator - o avatar possui habilidades específicas que permitem realizar determinadas tarefas e atingir certos objetivos.

Seguindo a lista de princípios, temos desafio e consolidação. Gee ressalta que, na escola, às vezes os estudantes com mais dificuldade não têm suficientes oportunidades para consolidar seu aprendizado; por outro lado, os bons estudantes não encontram desafios suficientes ao domínio das habilidades escolares adquiridas. A repetição é uma importante estratégia no ensino-aprendizagem e no Minecraft ela acontece pelo fato de o jogador-minerador precisar repetir uma série de procedimentos para construir cenários e objetos. Quanto mais experiência, mais rapidamente ele consegue construir e mais motivado se sente para se aventurar em novas e mais complexas conquistas.

Os bons games, defende Gee, dão as informações verbais "na hora certa" ou seja, quando os jogadores precisam delas e podem usá-las — ou "a pedido", ou seja, quando o jogador sente necessidade de informações, as deseja, está pronto para fazer bom uso delas. O Minecraft cumpre muito bem esse requisito, pois o jogador pode escolher o momento exato em que buscar determinada informação. $\mathrm{O}$ ambiente não é poluído por textos explicativos e ferramentas tutoriais. $\mathrm{O}$ inventário do jogo é uma espécie de loja que o jogador abastece conforme cria objetos no ambiente e pode acessá-los quando sentir necessidade.

Outro princípio são os sentidos contextualizados. Os games contextualizam os significados das palavras em termos das ações, imagens e diálogos a que elas se relacionam e mostram como eles variam através de diferentes ações, imagens e diálogos. Eles não disponibilizam apenas palavras em troca de palavras. O Minecraft contextualiza os significados das palavras em termos das ações, imagens e diálogos a que elas se relacionam. Um exemplo se dá durante a construção do mundo virtual, que se baseia nos objetos do mundo real. Assim, enquanto o avatar passeia pelo ambiente, ao clicar na tecla F5, aparece em qual bioma ele se encontra. Biomas são regiões no mundo do Minecraft com diferentes características geográficas, flora, altitude, temperaturas, classificações de umidade, céu e as cores de folhagem. Exemplos de biomas incluem a floresta, selva, deserto e planícies de gelo. 
comunicação \& educação • Ano XX • número 2 • jul/dez 2015

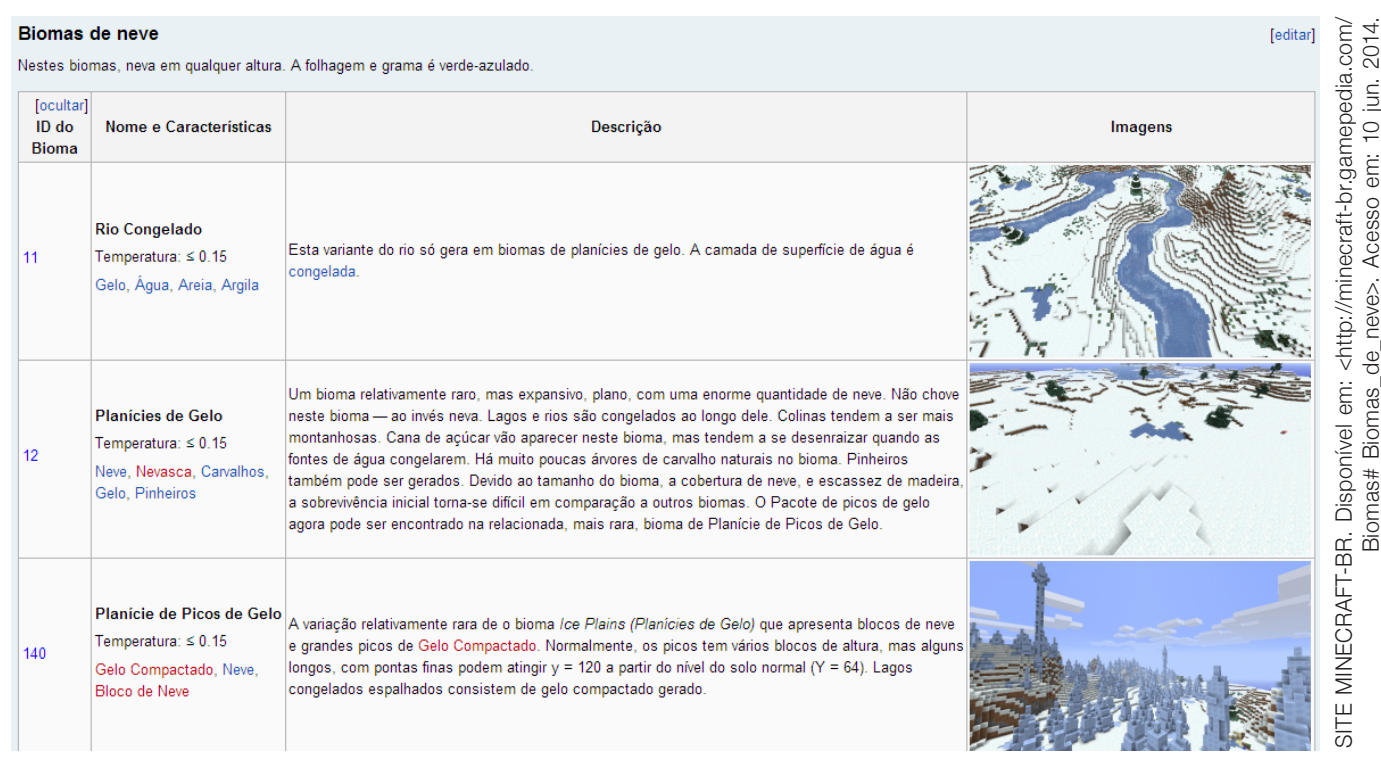

Figura 5: Biomas de neve do Minecraft

Um novo princípio é o da frustração prazerosa. Os games são percebidos como "factíveis", mas desafiadores. Ninguém consegue abarcar todas as possibilidades dentro do universo do Minecraft e isso faz com que os jogadores sintam prazer em enfrentar desafios e superar limites. Esse é um fator motivador para os aprendizes.

Os videogames encorajam os jogadores a pensar sobre as relações, desenvolvendo assim o pensamento sistemático. No mundo de Minecraft, tal como acontece no mundo real, cada ação tem um respectivo impacto. O jogador deve pensar nas consequências de seus atos porque influenciam tudo ao seu redor. Por exemplo, se o avatar não plantar árvores não terá madeira para construir certos objetos; se não cultivar trigo e irrigar diariamente a plantação, não terá pão e assim por diante.

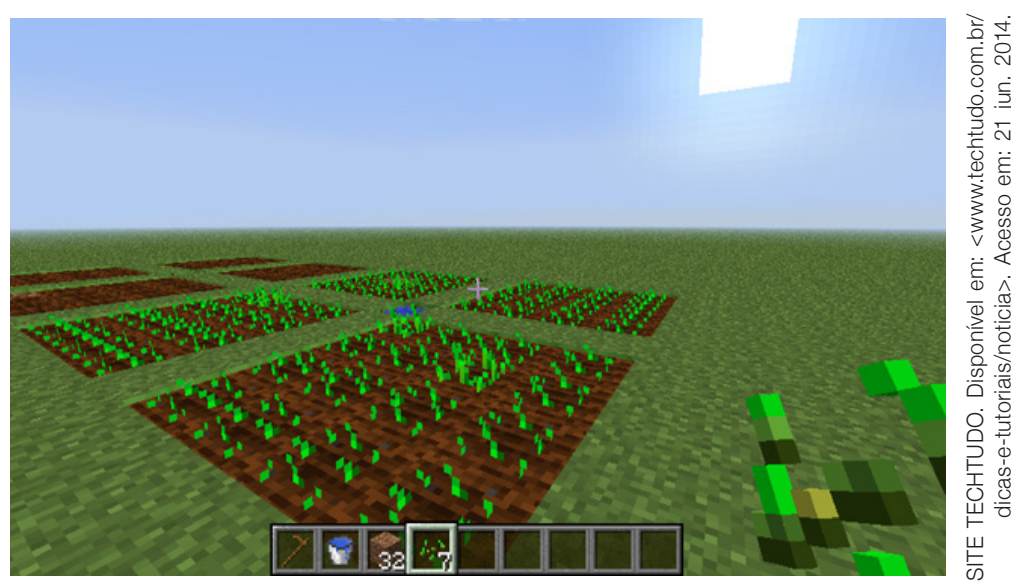

Figura 6: Cultura de trigo no Minecraft

Explorar, pensar lateralmente, repensar os objetivos: o Minecraft incentiva o pensamento não linear, pois não impõe caminhos e não sugere soluções. Cada jogador pode criar sua própria trajetória, diferente dos outros. Não tem 


\section{O potencial significativo de games na educação \\ - Luciana Coutinho Pagliarini de Souza e Angelica Caniello}

o certo e o errado, apenas probabilidades e conjeturas que podem ser repensadas a todo o momento.

Os personagens virtuais têm habilidades e conhecimentos próprios que emprestam ao jogador. Em um jogo de múltiplos jogadores, cada um trabalha em equipe, na qual cada membro contribui com suas habilidades próprias. O conhecimento central necessário para jogar é distribuído entre um conjunto de pessoas reais e seus personagens virtuais. Cada jogador deve dominar sua própria especialidade (função), mas entende o suficiente das especialidades dos demais para integrar-se e interagir com eles (compreensão transfuncional). Tais habilidades caracterizam os princípios: ferramentas inteligentes e conhecimento distribuído/equipes transfuncionais.

Por fim, encerrando a lista de princípios de Gee, vem a performance anterior à competência. Nos bons games, a performance vem antes da competência. Um ditado que bem se aplica ao Minecraft é o que diz que "é jogando que se aprende". Assim, por exemplo, no modo Survival todos os jogadores têm necessidade de criar meios para se defender dos monstros quando a noite cai. Para tanto, eles coletam recursos para construir um abrigo com iluminação no início do primeiro dia. Se o jogador não conseguir sobreviver ao ataque dos monstros, todos os itens em seu inventário permanecerão espalhados pelo lugar onde ele morreu, para serem recuperados e uma nova estratégia de defesa, mais eficaz, deverá ser pensada. Nessa trajetória inicial de tentativa e erro, o jogador ganha experiência e melhora a sua atuação.

\section{CONSIDERAÇÕES FINAIS}

Os estudos relacionados à Educomunicação reforçam a ideia de que conhecimento não é acúmulo de informações e que a hipermídia é uma ferramenta valiosa para promover o aluno da posição passiva de receptor de conteúdos para coautor de um universo híbrido de textos, imagens e sons. Os games utilizam a linguagem hipermediática e, por isso, têm um alto potencial de promover um aprendizado interativo e criativo.

Curioso notar que o Minecraft, que não foi desenvolvido para fins educacionais, cumpre com os requisitos de aprendizagem necessários para um bom jogo, na visão de Gee. Ele permite explorar e criar objetos com grande autonomia e compartilhar as experiências adquiridas com outros gamers. Além disso, dá "voz" ao usuário, que pode criar modificações dentro do jogo, impondo novos desafios e estimulando a fantasia de forma lúdica.

Schwartz ${ }^{15}$ faz uma crítica àqueles que acreditam que a escola é uma instituição falida, que o professor é um personagem ultrapassado e que estudar é para quem não tem mais o que fazer: "Vamos jogar em outra linha: a escola pode e precisa ser transformada, o professor tem um papel de liderança e mentoria, e estudar pode ser não apenas divertido, mas empolgante e inseparável de nossos sonhos, projetos e atitudes". Esse "jogo" Schwartz chama de

15 SCHWARTZ, op. cit. 
comunicação \& educação • Ano XX • número 2 • jul/dez 2015

Criatividade e defende que os profissionais de design instrucional poderão ampliar significativamente a participação criativa dos alunos quando integrarem suas plataformas ao universo dos games.

\section{REFERÊNCIAS}

FENÔMENO mundial, jogo Minecraft pode ganhar adaptação para o cinema. Folha de São Paulo. São Paulo, fev. 2014. Disponível em: <www1.folha.uol. com.br/tec/2014>. Acesso em: 15 maio 2014.

GEE, J., P. Bons videogames e boa aprendizagem. Revista Perspectiva, Florianópolis, v. 27 n. 1, jan./jun. 2009. Disponível em: <www.perspectiva. ufsc.br>. Acesso em: 1 jul. 2013.

HUIZINGA, Johan. Homo ludens. São Paulo: Perspectiva, 1999.

OROZCO GÓMEZ, G. Educomunicação: recepção midiática, aprendizagens e cidadania. São Paulo: Paulinas, 2014.

SANTAELLA, Lucia. Games e comunidades virtuais. In: EXPOSIÇÃO HIPERRELAÇÕES ELETRO DIGITAIS, Instituto Sérgio Motta e Santander Cultural, Porto Alegre, 2004.

Game também é cultura? Seminário Internacional Rumos do Jornalismo Cultural, São Paulo, 2012. Disponível em: <www.youtube.com/ watch?v= NZr5FnjWzTE $>$. Acesso em: 25 abr. 2013.

Comunicação ubíqua. São Paulo: Paulus, 2013.

SCHWARTZ, Gilson. Game "Conflitos globais" tenta quebrar paradigma e colocar jogos na escola. Globo.com, mar. 2010. Disponível em: <http:/ g1.globo.com/Noticias/Games/ 0,MUL1534669-9666,00.html>. Acesso em: 30 jun. 2013.

SOARES, I.O.; TUPY, F; SCHWARTZ, G. Educomunicação e Videogames: uma abordagem de interface aplicada para Gestão. XI SBGAMES. Brasília, nov. 2012. 